\title{
The role of lifestyle in health: the epidemiology and consequences of inactivity
}

\author{
B Y WILLIAM H. DIETZ \\ New England Medical Center, Division of Pediatric Gastroenterology and Nutrition, \\ Box 213, 750 Washington Street, Boston, MA 02111, USA
}

'Sedentary activity' constitutes an oxymoron. 'Inactivity' is a more appropriate term to describe the time spent in sedentary behaviours. Inactivity can be defined as a state in which bodily movement is minimal. In terms of energy expenditure, inactivity represents a state or behaviour for which energy expenditure approximates resting metabolic rate. However, the study of inactivity as a behaviour rather than an account of the energy spent in sedentary pursuits may offer a richer assessment of factors that contribute to obesity or other diseases. Inactive behaviours include television viewing, reading, working at a computer, talking with friends or on the telephone, driving a car or commuting, meditation or eating (Ainsworth et al. 1993).

Historically, efforts have been made to quantify activity, to determine the validity and reliability of estimates of activity, and to determine the effects of activity on morbidity and mortality. The quantification of inactivity, and the assessment of the morbidity and mortality attributable to inactivity have received far less attention. Because inactivity has generally been viewed as part of a continuum of activity, most of the effects of inactivity must be inferred from studies of activity. Nonetheless, the adverse health effects of inactivity may be as significant as the beneficial health effects of vigorous activity. In the present brief review, we will examine the evidence that inactivity exerts effects on health that are independent of the effects of activity. We will then explore the morbidity and mortality associated with inactivity, the epidemiology of inactivity, and recommendations for change.

\section{INACTIVITY IS NOT THE OPPOSITE OF ACTIVITY}

Few analyses have been designed to examine whether inactivity and activity exert independent effects on health outcomes. Obesity represents an exception. In the National Children and Youth Fitness Survey (Pate \& Ross, 1987), both the parent's and teacher's rating of a child's activity level and time spent watching television had independent effects on the prevalence of obesity. Increased activity was inversely associated, whereas television viewing was directly and independently associated, with the prevalence of obesity (S. L. Gortmaker, unpublished results). These relationships persisted after the introduction of controls for age, gender, parental activity levels, parental exercise with child, or time spent in physical-education classes or recess in school. In a second study (Ching et al. 1996), the effect of activity and television viewing on the 2-year incidence of obesity was examined in adult males studied in the Health Professionals Follow-up Study. Logistic regression indicated that vigorous activity level and weekly television viewing independently affected the 2-year incidence of obesity. Men who watched over $21 \mathrm{~h}$ of television per week were $40 \%$ more likely to become overweight over a 2 -year period than men who watched less that $1 \mathrm{~h}$ per week.

Examination of changes in energy spent on activity with age provide support for the 
distinction of inactivity, activity and the energy spent on activity. The physical activity level (PAL) can be estimated from the quotient of total energy expenditure, measured with doubly-labelled water $\left({ }^{2} \mathrm{H}_{2}{ }^{18} \mathrm{O}\right)$, divided by resting metabolic rate, measured by indirect calorimetry. Although the PAL includes the thermic effect of food, most of the variance in the PAL is attributable to variations in the energy spent on activity.

Expressed as a function of resting metabolic rate, the PAL increases from 1.35 in infants (Davies et al. 1995b) to 1.69 in adolescent females and 1.79 in adolescent males (Bandini et al. 1990). Children of 5-12 years of age have intermediate values (Livingstone et al. 1992; Fontvielle et al. 1993). Although these data would suggest that children are less active, infants and young children spend substantial periods of time sleeping, and may have lower metabolic rates during sleep (Davies et al. 1995a). In adults, the PAL ranges between 1.45 and 1.95 (Schulz \& Schoeller, 1994), and declines with age (Rising et al. 1994; Schulz \& Schoeller, 1994). Although no significant gender differences exist in young children (Davies et al. 1995a), adult males appear more active than adult females (Schulz \& Schoeller, 1994). Adults in developing countries expend more energy than adults in industrialized countries (Singh et al. 1989).

If reduced physical activity constitutes a risk factor for the development of obesity, periods of reduced energy expenditure should coincide with periods of increased risk for the development of obesity in the population. However, children, who have the lowest incidence of obesity, also spend the least energy on activity. Adolescence appears to be a period of increased risk for the development of obesity in girls. Nonetheless, adolescent girls do not spend substantially less energy on activity than other groups.

These findings suggest that activity and inactivity may have independent effects, at least on the prevalence of obesity. The independent effects of activity and inactivity on outcomes other than obesity have rarely been examined. In part, lack of other data may reflect the use of activity as a continuous variable that extends from inactivity to vigorous activity. The assumption implicit in this approach is that the energy spent on each stratum of activity can be quantified, and that the effects of the level of activity on the outcome of interest are mediated by energy expenditure. The effects of vigorous activity or inactivity on health may reflect different mechanisms or associations that operate at the extremes of activity, and have independent effects on the health of populations. For example, inactivity may lead to increases in body fatness, whereas vigorous activity may enhance cardiovascular fitness and reduce cardiovascular disease, independent of the effects of vigorous activity on fatness.

\section{MORBIDITY AND MORTALITY ASSOCIATED WITH INACTIVITY}

Few studies have examined the morbidity and mortality of inactivity. However, a number of studies have compared morbidity or mortality in physically-active groups with morbidity and mortality in those who do not participate in leisure-time physical activity. These studies do not generally account for activity at work or activities intermediate between inactivity and vigorous activity. Nonetheless, crude estimates of the effect of inactivity can be obtained from such studies.

Incidence rates of diabetes appear highest among men with the least leisure-time physical activity, even after adjustment for BMI and family history of diabetes (Helmrich et al. 1991). The relative risk of subsequent myocardial infarction appears highest among 
the least-active individuals, and decreases as physical activity increases (Paffenbarger $e$ t al. 1986; Berlin \& Colditz, 1990; Morris et al. 1990; Lakka et al. 1994). Inactivity increases the risk of stroke, independent of its effect on risk factors for coronary artery disease (Wannamathee \& Shaper, 1992).

Two separate estimates based on studies of activity have indicated that sedentary lifestyles contribute substantially to the morbidity and mortality of chronic diseases in the United States. The earliest of these studies (Hahn et al. 1990) concluded that a sedentary lifestyle ranked only behind cigarette smoking and obesity as a contributor to deaths from nine chronic diseases, including coronary heart disease, stroke, and colo-rectal cancer. Sedentary lifestyles were estimated to account for approximately $23 \%$ of all deaths from these causes. These observations were supported by a second study (McGinnis \& Foege, 1993) that suggested that diet and activity patterns accounted for about 300000 deaths in the United States in 1990 , or $14 \%$ of the actual causes of death. In view of the disparate methodologies employed by the two studies, the concurrence of the two estimates is surprising.

One of the earliest observations of the role of diet and activity in the genesis of obesity suggested that inactivity might play a more important role than diet in the development of obesity (Johnson et al. 1956). Stronger relationships between the prevalence of obesity and inactivity than between obesity and several dietary variables in Great Britain supports this possibility (Prentice \& Jebb, 1995). The inverse relationship observed between the energy spent on activity and the level of fatness in cross-sectional studies of children (Davies et al. 1995a) and adults (Schulz \& Schoeller, 1994) indicates either that decreased energy expenditure precedes the development of obesity or accompanies it.

Several prospective studies in various age-groups have linked inactive behaviours with changes in body fatness. As indicated previously, time spent viewing television by male health professionals significantly increased the 2-year incidence of obesity (Ching et al. 1996). The National Health and Nutrition Examination Follow-up Study demonstrated that low recreational physical activity levels were associated with both the risk of weight gain over a 10-year period as well as obesity present at baseline and at follow-up (Williamson et al. 1993). In contrast, no significant relationship could be demonstrated between baseline physical activity and weight gain in either men or women. These findings suggested that low physical activity increased the risk of incident obesity, and that obesity may also contribute to low levels of physical activity. A similar relationship between activity and the risk of subsequent weight gain has been observed among children and adults of both genders in Finland (Rissanen et al. 1991; Raitakari et al. 1994). Inactivity is also increased in the winter and decreased in the summer (Dannenberg et al. 1989), and may contribute to seasonal variations in fatness (Dietz \& Gortmaker, 1984).

Whether the relationship between inactivity and the development of obesity is a consequence of a reduced level of energy expenditure, or whether inactivity is a marker for other behaviours that lead to obesity remains unclear.

\section{EPIDEMIOLOGY OF ACTIVITY}

Although few studies have focused on inactivity, the epidemiology of activity can be used to infer changes in inactivity. Physical activity decreases as maturation proceeds during childhood, and declines are greater in females than in males (Armstrong et al. 1990; Sallis, 
1993). Heart-rate monitoring of children in the United States indicated that prepubescent children spent approximately $30 \mathrm{~min} / \mathrm{d}$ at or above the aerobic training threshold, defined as a heart rate above $60 \%$ of heart-rate reserve based on predicted heart rate. However, pubescent and post-pubescent children spent less than $10 \mathrm{~min} / \mathrm{d}$ with heart rates at the same level (Janz et al. 1992). Findings in 11-16-year-old British children were comparable (Armstrong et al. 1990). Additional supportive data were subsequently published from the Youth Risk Behavior Surveillance System, a nationally representative survey of highschool students in the United States, conducted by the Centers for Disease Control (Heath et al. 1994). Girls were less likely to participate in physical activity than were boys. About $75 \%$ of girls, but only $50 \%$ of boys reported no vigorous activity in the previous 3-week period. During the high-school years, no significant changes occurred in the activity levels of boys, and no significant differences were observed across ethnic groups. However, vigorous activity levels decreased significantly by grade for girls in all ethnic groups. The greatest decreases occurred among African-American girls. Only $9 \%$ of black girls reported vigorous physical activity by their last year in high school (Heath et al. 1994). Parallel trends have been noted in other population samples (Wolf et al. 1993).

The prevalence of a sedentary lifestyle in adults in the United States has gradually increased over the last two decades. Estimates by Choi (1975) derived from the Health Interview Survey, a national sample of 58000 persons living in 20000 households, indicated that $51 \%$ of males and females reported no regular exercise. In both genders, the percentage of individuals who reported no regular exercise increased with age, and decreased with family income levels. By 1991, according to the Behavioral Risk Factor Surveillance System, the percentages of men and women who reported no physical activity had increased to 58\% for both genders. As in the 1975 survey, the prevalence of no regular exercise increased with age, decreased with family income levels, and was greater for other ethnic groups than for non-Hispanic whites (Centers for Disease Control, 1993a). AfricanAmerican women consistently appear to have lower levels of physical activity, even after adjustment for a variety of confounding variables, including age, income, and BMI (Washburn et al. 1992). National Surveys from North America have consistently indicated an increase in inactivity with age, and an inverse relationship between inactivity and socioeconomic status (Stephens et al. 1985).

Activity reflects a strong familial component. The observation that levels of activity in families are more highly correlated within generations than across generations suggests that levels of activity may reflect an environmental as well as a genetic influence (Perusse et al. 1988, 1989). The familial patterns of inactivity have not been studied as intensively. Like the Canadian studies (Perusse et al. 1988, 1989), we found that measures of vigorous activity were better correlated between spouses than between mother-daughter or father-daughter pairs (A. Must, P. L. Y. H. Ching and W. H. Dietz, unpublished results). In contrast, time spent watching television was better correlated within families, independent of the effects of parental obesity, education level and ethnicity.

The tracking (likelihood that a relative percentile rank with respect to a characteristic will persist) of sedentary activity during adolescence is better in males than females, but increases with age in both genders. In addition, inactivity appears to track better than physical activity from adolescence into young adulthood (Raitakari et al. 1994). 
WHAT DO INACTIVE PEOPLE DO?

Few studies have examined carefully how adults partition their time over the course of the day. The most relevant study, conducted between 1976-7, relied on the experience sampling method (Kubey \& Csikszentmihalyi, 1990). Adults ( $n$ 107) employed in the Chicago area were equipped with an electronic pager that was activated seven to nine times daily over the course of 1 week. When the pager was activated, the subjects were asked to provide information on a questionnaire regarding their current activity. Individuals spent approximately $40 \%$ of their time in work, $40 \%$ of their time at home, and $20 \%$ in other activities. In general, subjects were not engaged in vigorous activities. Television accounted for the principal leisure activity, and was watched exclusively or in association with other activities for $40 \%$ of leisure time. Nonetheless, the estimates of television time $(1.4 \mathrm{~h} / \mathrm{d})$ provided by this study were considerably lower than those from more recent surveys. For example, in 1992-3, women over the age of 55 years watched over $44 \mathrm{~h}$ of television per week (Neilsen Media Research, 1993). These data suggest that television viewing far exceeds the time spent in any other leisure activity, and represents the principal sedentary behaviour in the United States. Television viewing among adult women appears inversely associated with habitual physical activity levels (Human Nutrition Information Service, 1989).

Television viewing has been directly associated with fatness in cross-sectional studies of children (Dietz \& Gortmaker, 1985), adolescents (Dietz \& Gortmaker, 1985), and adults (Tucker \& Friedman, 1989; Gortmaker et al. 1990; Tucker \& Bagwell, 1991). Although the association between television viewing and obesity has not been observed in all studies (Robinson et al. 1993; Wolf et al. 1993; Robinson \& Killen, 1995), failure to demonstrate an association between television viewing and obesity may have been attributable to lack of a representative sample, or to errors associated with the measurement of television viewing.

Comparison of the relationship between television viewing and the prevalence of obesity in 12-17-year-old adolescents studied in 1967 in the National Health Examination Survey (Dietz \& Gortmaker, 1984) with the relationship among 10-15-year-old children studied in the National Longitudinal Survey of Youth in 1990 suggests that the strength of the relationship has increased considerably (Gortmaker et al. 1996). Furthermore, almost onethird of the 10-15-year-old children and adolescents studied in 1990 watched more than $5 \mathrm{~h}$ of television daily. After adjustment for overweight at baseline, gender, poverty, and mother's ethnicity, education, marital status, and employment, the relative risk of overweight was $5 \cdot 3$ times greater for children who watched more than $5 \mathrm{~h}$ of television daily compared with those who watched $0-2 \mathrm{~h}$. Television viewing also appeared directly associated with the incidence of obesity, and inversely associated with the remission of obesity.

Television viewing can affect energy expenditure either through the displacement of more vigorous activities or through its effects on metabolic rate. When television was introduced into a community that previously had none, participation in sports declined (Williams \& Handford, 1986). Parents commonly report that television exerts a hypnotic effect on children, akin to a trance-like state. We speculated some time ago that this state might be associated with a lower metabolic rate. At least one study has presented data that suggested that metabolic rate was lower in children while they were watching television, although the calorimetry in that study found resting metabolic rates that were 
approximately $15 \%$ greater than metabolic rates estimated from age, gender and weight (Klesges et al. 1993). Our studies failed to demonstrate a significant difference in metabolic rate among pre-adolescent girls measured when they were reading, watching television, or sitting quietly in a chair doing nothing (Dietz et al. 1994). Video games are commonly considered a prevalent form of inactivity. However, $\mathrm{O}_{2}$ consumption while playing a video game indicated that the level of energy expenditure was $80 \%$ greater than resting metabolic rate (Segal \& Dietz, 1991). The energy expended in other sedentary behaviours, such as working at a computer have not been examined, but are probably similar.

\section{THE EFFECTS OF INACTIVITY MAY NOT BE MEDIATED BY REDUCED ENERGY EXPENDITURE}

The potential effect of inactivity on dietary intake and other cardiovascular risk behaviours appears a fruitful area for further investigation. For example, although television viewing clearly constitutes a sedentary behaviour, the effects of television on obesity are probably not mediated exclusively by reduced energy expenditure. For the last 20 years, food has constituted the most-heavily-advertised product on children's television in the United States (Barcus \& McLaughlin, 1978; Kaufman, 1980; Story \& Faulkner, 1990; Taras \& Gage, 1995). Furthermore, television viewing appears closely linked to the consumption of foods advertised on television for children (Clancey-Hepburn et al. 1974; Taras et al. 1989; Robinson \& Killen, 1995). In an ethnically heterogeneous sample of young adolescents, dietary fat intake was significantly associated with the number of weekly hours spent viewing television (Robinson \& Killen, 1995).

Recent studies in adolescents (Lytle et al. 1995) and adults (Simoes et al. 1995) have demonstrated significant relationships between inactivity and other adverse health practices, such as consumption of less-healthy foods or increased fat intake. Inactive individuals tended to consume increased quantities of dietary fat, even after adjustment for age, ethnicity, education, and BMI. Interestingly, fat intake also increased with cigarette smoking. In both adolescents (Escobedo et al. 1993; Lytle et al. 1995) and adults (Dannenberg et al. 1989) inactivity has also been associated with increased rates of cigarette smoking. Among adolescents, the covariance of these behaviours increases with age (Lytle et al. 1995). The demonstration in young Finns that sedentary activity predicted the initiation of smoking and increased consumption of saturated fatty acids (Raitakari et al. 1994) suggests that the covariance of inactivity with other behaviours that predispose to cardiovascular disease is not limited to North American populations.

These data suggest that inactivity tends to cluster with other health behaviours that have an adverse effect on the quantity and location of body fat deposition. Whether the cluster of these behaviours reflects physiological, behavioural, or environmental effects remains unclear. One possibility is that for individuals who play sports regularly, smoking and alcohol use may have an immediate and recognizable impact on performance that serves to discourage these behaviours. No such adverse effects may occur among sedentary individuals. However, because inactivity is associated with increased body fat (Schulz \& Schoeller, 1994), and because both smoking (Troisi et al. 1991) and alcohol (Haffner et al. 1986; Troisi et al. 1991) increase visceral fat deposition, the net effects of the covariance of inactivity with other behaviours is to increase the risk of the morbidity and mortality of obesity. 


\section{INTERVENTIONS}

Inactivity appears to be the best target for population-based interventions for coronary heart disease, because its prevalence is so much greater than elevated serum cholesterol, cigarette smoking, overweight, hypertension, or diabetes (Centers for Disease Control, 1990, 1993a). Furthermore, interventions directed at reductions in activity may be two times more cost-effective than interventions aimed at other cardiovascular risk factors, such as hypertension, smoking, or hypercholesterolaemia (Centers for Disease Control, 1993b). Increases in activity over time have been associated with slower rates of weight gain (Owens et al. 1992). Likewise, the initiation of moderately-vigorous sports activity has been associated with a lower risk of death over a 10-year period of follow-up (Paffenbarger et al. 1993). Increases in activity may also be more responsive to community-based interventions than other cardiovascular risk factors. For example, in the Minnesota Heart Health Program, regular physical activity increased more rapidly than did the secular trend in activity (Luepker et al. 1994), whereas no effect of the intervention was seen on cholesterol levels, cigarette smoking, blood pressure, BMI, or coronary heart disease risk score.

Two strategies can be pursued to address the role of inactivity in the genesis of obesity or morbidity from other diseases. The first is to increase activity. The most recent recommendations from the Centers for Disease Control and Prevention and the American College of Sports Medicine suggested that every adult should accumulate $30 \mathrm{~min}$ or more of moderate-intensity physical activity on most and preferably all days of the week (Pate et al. 1995). The greatest impact of increased activity will be on those who are the most inactive at baseline (Pate et al. 1995).

The alternative approach is to reduce inactivity. This approach has rarely been tried. However, an innovative and provocative study by Epstein et al. (1995) suggested that reductions in inactivity may be more successful in the treatment of obesity than increases in activity in children and young adolescents. Epstein et al. (1995) established three groups of overweight children and their parents. All groups received standardized-diet and behaviour-modification instructions, but were randomized to receive reinforcement for increases in exercise, reinforcement for reductions in inactivity, or reinforcement for increases in exercise and reductions in inactivity. The most sustained weight losses occurred in the group reinforced for reductions in inactivity. Furthermore, attitudes about vigorous activity were significantly more positive in the group reinforced for reductions in inactivity than in the other two groups, perhaps because vigorous activity was perceived as a voluntary choice rather than one pressured by positive reinforcement. The adverse effects of positive reinforcement for exercise are supported by the finding that children whose parents encouraged them to be active or play sports were not more active (Sallis et al. 1992a).

Confirmation that health behaviours covary will significantly affect the target of an intervention. For example, if health behaviours covary, a strategy that targets beliefs or motivations that underlie more than one health behaviour will be more appropriate than a campaign that targets the beliefs or behaviour that underlie one specific behaviour (Lytle et al. 1995).

The development of a successful intervention will depend on the identification of the attitudes and beliefs about the barriers to inactivity, the perceived potential benefits of becoming more active, and the barriers to implementation of the intervention. Attitudes that 
have distinguished those who intended to exercise from those who did not included the perception of activity as enjoyable, interesting, exciting, pleasant and of benefit (Collette et al. 1994). Self-efficacy, and social and family support appear equally pertinent to increased activity (Reynolds et al. 1990; Sallis et al. 1992b).

The inverse association of leisure activity with socio-economic class suggests that the opportunity for vigorous activity may have become a luxury. Related factors that restrict the opportunity for activity are lack of facilities or access to low-cost facilities for exercise, or concerns about neighbourhood safety, particularly for children. A recent survey conducted by the Shape Up America campaign found that neighbourhood safety and lack of affordable recreational facilities were cited twice as often as obstacles to physical activity by low-income respondents (Barbara Moore, Shape Up America, personal communication).

Interventions to reduce inactivity in the entire population may not be appropriate for some subsets of the population. For example, in contrast to middle-class Caucasian women who frequently view leisure time as an opportunity to engage in vigorous activity, AfricanAmerican women view leisure time as an opportunity to rest (Kumanyika et al. 1992). Likewise, differences in the perception of ideal weight (Kumanyika et al. 1993) or the adverse effects of obesity may require the development of ethnic-group-specific messages to encourage the reduction of inactivity. Because of the need for autonomy, older adolescents may be less likely to respond to an intervention aimed at the family. However, because television time correlates better within families than measures of activity, a logical strategy for younger children may be to develop interventions aimed at the reduction of time spent watching television by families.

\section{AREAS FOR ADDITIONAL INVESTIGATION}

Inactivity represents an understudied behaviour that is associated with adverse health consequences. Successful reductions in inactivity may provide the most cost-effective approach to the treatment of obesity and the prevention of cardiovascular disease. However, neither the relevance to health of behaviours other than time spent viewing television nor the natural history of inactivity has been well characterized. Developmental periods when formerly active individuals become inactive, aside from adolescence in girls, have not been identified. Factors that account for the rapid declines in activity, factors that reinforce inactivity, or factors that sustain activity over time have not been established. Likewise, whether inactivity exerts its effect on morbidity and mortality through reduced energy expenditure, lack of intense exercise that improves cardiovascular fitness, or through the covariance of inactivity and other behaviours that have an adverse effect on health remains unclear. Clarification of each of these areas is essential to target the time and focus of interventions.

Partial support was provided by NIH grants nos. RR-00088, DK/HD 50537 and P30DK46200. I am grateful to Drs Bandini, Gortmaker, Must and Rosenfield for their review and comments on early versions of the manuscript, and to Eileen Holman for her secretarial assistance. 


\section{REFERENCES}

Ainsworth, B. E., Haskell, W. L., Leon, A. S., Jacobs, D. R. Jr, Montoye, H. J., Sallis, J. F. \& Paffenbarger, R. S. Jr (1993). Compendium of physical activities: classification of energy costs of human physical activities. Medical Science Sports and Exercise 25, 71-80.

Armstrong, N., Balding, J., Gentle, P. \& Kirby, B. (1990). Patterns of physical activity among 11 to 16 year old British children. British Medical Journal 301, 203-205.

Bandini, L. G., Schoeller, D. A. \& Dietz, W. H. (1990). Energy expenditure in obese and non-obese adolescents. Pediatric Research 27, 198-203.

Barcus, E. F. \& McLaughlin, L. (1978). Food Advertising on Children's Television: An Analysis of Appeals and Nutritional Content. Newtonville, MA: Action for Children's Television.

Berlin, J. A. \& Colditz, G. A. (1990). A meta-analysis of physical activity in the prevention of coronary heart disease. American Journal of Epidemiology 132, 612-628.

Centers for Disease Control (1990). Coronary heart disease attributable to sedentary lifestyle - selected states, 1988. Morbidity and Mortality Weekly Report 39, 541-544.

Centers for Disease Control (1993a). Prevalence of sedentary lifestyle - Behavioral Risk Factor Surveillance System, United States. Morbidity and Mortality Weekly Report 42, 576-579.

Centers for Disease Control (1993b). Public health focus: physical activity and the prevention of coronary heart disease. Morbidity and Mortality Weekly Report 42, 669-672.

Ching, P. L. Y. H., Willett, W. C., Rimm, E. B., Colditz, G. A., Gortmaker, S. L. \& Stampfer, M. J. (1996). Activity level and risk of overweight in male health professionals. American Journal of Public Health 86, $25-30$.

Choi, J. W. (1975). Exercise and Participation in Sports Among Persons 20 Years of Age and Over: United States. Advance Data, National Center for Health Statistics. Hyattsville, MD: US Department of Health Education and Welfare.

Clancey-Hepburn, K., Hickey, A. A. \& Nevill, G. (1974). Children's behavior responses to TV food advertisements. Journal of Nutrition Education 6, 93-96.

Colette, M., Godin, G., Bradet, R. \& Gionet, N. J. (1994). Active living in communities: understanding the intention to take up physical activity as an everyday way of life. Canadian Journal of Public Health 85, $418-421$.

Dannenberg, A. L., Keller, J. B., Wilson, P. W. F. \& Castelli, W. P. (1989). Leisure time physical activity in the Framingham offspring study. Description, seasonal variation, and risk factor correlates. American Journal of Epidemiology 129, 76-88.

Davies, P. S. W., Gregory, J. \& White. A. (1995a). Physical activity and body fatness in preschool children. International Journal of Obesity 19, 6-10.

Davies, P. S. W., Wells, J. C. K., Fieldhouse, C. A., Day, J. M. E. \& Lucas, A. (1995b). Parental body composition and infant energy expenditure. American Journal of Clinical Nutrition 61, 1026-1029.

Dietz, W. H., Bandini, L. G., Morelli, J. A., Peers, K. F. \& Ching, P. L. Y. H. (1994). Effect of sedentary activities on resting metabolic rate. American Journal of Clinical Nutrition 59, 556-559.

Dietz, W. H. \& Gortmaker, S. L. (1984). Factors within the physical environment associated with childhood obesity. American Journal of Clinical Nutrition 39, 619-624.

Dietz, W. H. \& Gortmaker, S. L. (1985). Do we fatten our children at the TV set? Television viewing and obesity in children and adolescents. Pediatrics 75, 807-812.

Epstein, L. E., Valoski, A. M., Vara, L. S., McCurley, J., Wisniewski, L., Kalarchian, M. A., Klein, K. R. \& Shrager, L. R. (1995). Effects of decreasing sedentary behavior and increasing activity on weight change in obese children. Health Psychology 14, 109-115.

Escobedo, L. G., Marcus, S. E., Holtzman, D. \& Giovino, G. A. (1993). Sports participation, age at smoking initiation, and the risk of smoking among US high school students. Joumal of the American Medical Association 269, 1391-1395.

Fontvielle, A. M., Harper, I. T., Ferraro, R. T., Spraul, M. \& Ravussin, E. (1993). Daily energy expenditure by five-year-old children, measured by doubly labeled water. Journal of Pediatrics 123, 200-207.

Gortmaker, S. L., Dietz, W. H. \& Cheung, L. W. Y. (1990). Inactivity, diet, and the fattening of America. Journal of the American Dietetic Association 90, 1247-1255.

Gortmaker, S. L., Must, A., Sobol, A. M., Peterson, K., Colditz, G. A. \& Dietz, W. H. (1996). Television viewing as a cause of increasing obesity among children in the United States, 1986-1990. Archives of Pediatric and Adolescent Medicine 150, 356-362. 
Haffner, S. M., Stern, M. P., Hazuda, H. P., Pugh, J., Patterson, J. K. \& Malina, R. (1986). Upper body and centralized adiposity in Mexican Americans and non-Hispanic whites: relationship to body mass index and other behavioral and demographic variables. International Journal of Obesity 10, 493-502.

Hahn, R. A., Teutsch, S. M., Rothenberg, R. B. \& Marks, J. S. (1990). Excess deaths from nine chronic diseases in the United States, 1986. Journal of the American Medical Association 264, 26542659.

Heath, G. W., Pratt, M., Warren, C. W. \& Kann, L. (1994). Physical activity patterns in American high school students. Results from the 1990 Youth Risk Behavior Survey. Archives of Pediatric and Adolescent Medicine 148, 1131-1136.

Helmrich, S. P., Ragland, D. R., Leung, R. W. \& Paffenbarger, R. S. Jr (1991). Physical activity and reduced occurrence of non-insulin-dependent diabetes mellitus. New England Journal of Medicine 325, 147-152.

Human Nutrition Information Service (1989). Continuing Survey of Food Intake by Individuals. Washington, DC: US Department of Agriculture.

Janz, K. F., Golden, J. C., Hansen, J. R. \& Mahoney, L. T. (1992). Heart rate monitoring of physical activity in children and adolescents: the Muscatine study. Pediatrics 89, 256-261.

Johnson, M. L., Burke, B. S. \& Mayer, J. (1956). Relative importance of inactivity and overeating in the energy balance of obese high school girls. American Journat of Clinical Nutrition 4, 37-44.

Kaufman, L. (1980). Prime-time nutrition. Journal of Communications 30, 37-46.

Klesges, R. C., Shelton, M. L. \& Klesges, L. M. (1993). The effects of television on metabolic rate: potential implications for childhood obesity. Pediatrics 91, 281-286.

Kubey, R. \& Czikszentmihalyi, M. (1990). Television and the Quality of Life: How Viewing Shapes Everyday Experiences. Hillsdale, NJ: Lawrence Erlbaum Associates.

Kumanyika, S. K., Morssink, C. \& Agurs, T. (1992). Models for diet and weight change in African-American women: identifying cultural components. Ethnicity and Disease 2, 166-175.

Kumanyika, S. K., Wilson, J. F. \& Guilford-Davenport, M. (1993). Weight-related attitudes and behaviors of black women. Journal of the American Dietetic Association 93, 416-422.

Lakka, T. A., Venalainen, J. M., Rauramaa, R., Salonen, R., Tuomilehto, J. \& Salonen, J. T. (1994). Relation of leisure-time physical activity and cardiorespiratory fitness to the risk of acute myocardial infarction in men. New England Journal of Medicine 330, 1549-1554.

Livingstone, M. B. E., Coward, W. A., Prentice, A. M., Davies. P. S. W., Strain, J. J., McKenna, P. G., Mahoney, C. A., White, J. A., Stewart, C. M. \& Kerr, M.-J. J. (1992). Daily energy expenditure in free-living children: comparison of heart-rate monitoring with the doubly labeled water $\left({ }^{2} \mathrm{H}_{2}{ }^{18} \mathrm{O}\right)$ method. American Journal of Clinical Nutrition 56, 343-352.

Luepker, R. V., Murray, D. M., Jacobs, D. R. Jr, Mittelmark, M. B., Bracht, N., Carlaw, R., Crow, R., Elmer, P., Finnegan, J., Folsom, A. R., Grimm, R., Hannan, P. J., Jeffrey, R., Lando, H., McGovern, P., Mullis, R., Perry, C. L., Pechacek, T., Pirie, P., Sprafka, J. M., Weisbrod, R. \& Blackburn, H. (1994). Community education for cardiovascular disease prevention: risk factor changes in the Minnesota Heart Health Program. American Journal of Public Health 84, 1383-1393.

Lytle, L. A., Kelder, S. H., Perry, C. L. \& Klepp, K.-I. (1995). Covariance of adolescent health behaviors: the Class of 1989 Study. Health Education Research 10, 133-146.

McGinnis, J. M. \& Foege, W. H. (1993). Actual causes of death in the United States. Journal of the American Medical Association 270, 2207-2212.

Morris, J. N., Clayton, D. G., Everitt, M. G., Semmence, A. M. \& Burgess, E. H. (1990). Exercise in leisure time: coronary attack and death rates. British Heart Journal 63, 325-334.

Neilsen Media Research (1993). 1992-1993 Report on Television. Northbrook, IL: A. C. Neilsen Co.

Owens, J. F., Matthews, K. A., Wing, R. R. \& Kuller, H. (1992). Can physical activity mitigate the effects of aging in middle aged women? Circulation 85, 1265-1270.

Paffenbarger, R. S., Hyde, R. T., Wing, A. L. \& Hsieh, C.-C. (1986). Physical activity, all-cause mortality, and longevity of college alumni. New England Journal of Medicine 314, 605-613.

Paffenbarger, R. S. Jr, Hyde, R. T., Wing, A. L., Lee, I.-M., Jung, D. L. \& Kampert, J. B. (1993). The association of changes in physical-activity level and other lifestyle characteristics with mortality among men. New England Journal of Medicine 328, 538-545.

Pate, R. R., Pratt, M., Blair, S. N., Haskell, W. L., Macera, C. A., Bouchard, C., Buchner, D., Ettinger, W., Heath, G. W., King, A. C., Kriska, A., Leon, A. S., Marcus, B. H., Morris, J., Paffenbarger, R. S. Jr, Patrick, K., Pollock, M. L., Rippe, J. M., Sallis, J. \& Wilmore, J. H. (1995). Physical activity and public health. A recommendation from the Centers for Disease Control and Prevention and the American College of Sports Medicine. Journal of the American Medical Association 273, 402-407. 
Pate, R. R. \& Ross, J. G. (1987). National children and youth fitness survey: factors associated with healthrelated fitness. Journal of Physical Education, Recreation and Dance 58, 93-96.

Perusse, L., LeBlanc, C. \& Bouchard, C. (1988). Familial resemblance in lifestyle components: results from the Canada Fitness Survey. Canadian Joumal of Public Health 79, 201-205.

Perusse, L., Tremblay, A., LeBlanc, C. \& Bouchard, C. (1989). Genetic and environmental influences on level of habitual physical activity and exercise participation. American Journal of Epidemiology 129, 1012-1022.

Prentice, A. M. \& Jebb, S. A. (1995). Obesity in Britain: gluttony or sloth? British Medical Joumal 311, 437-439.

Raitakari, O. T., Porkka, K. V. K., Taimela, S., Telama, R., Rasanen, L. \& Viikara, J. S. A. (1994). Effects of persistent physical activity and inactivity on coronary risk factors in children and young adults. The Cardiovascular Risk in Young Finns Study. American Journal of Epidemiology 140, 195-205.

Reynolds, K. D., Killen, J. D., Bryson, S. W., Maron, D. J., Taylor, C. B., Maccoby, N. \& Farquhar, J. W. (1990). Psychosocial predictors of physical activity in adolescents. Preventive Medicine 19, 541-551.

Rising, R., Harper, I. T., Fontvielle, A. M., Ferraro, R. T., Spraul, M. \& Ravussin, E. (1994). Determinants of total daily energy expenditure: variability in physical activity. American Journal of Clinical Nutrition 59, $800-804$.

Rissanen, A. M., Heliovaara, M., Knekt, P., Reuanen, A. \& Aromaa, A. (1991). Determinants of weight gain and overweight in adult Finns. European Joumal of Clinical Nutrition 45, 419-430.

Robinson, T. N., Hammer, L. D., Killen, J. D., Kraemer, H. C., Wilson, D. M., Hayward, C. \& Taylor, C. B. (1993). Does television viewing increase obesity and reduce physical activity? Cross-sectional and longitudinal analyses among adolescent girls. Pediatrics 91, 273-280.

Robinson, T. N \& Killen, J. D. (1995). Ethnic and gender differences in the relationships between television viewing and obesity, physical activity, and dietary fat intake. Journal of Health Education 26, Suppl., 91-98.

Sallis, J. F. (1993). Epidemiology of physical activity and fitness in children and adolescents. Critical Reviews in Food Science and Nutrition 33, 403-408.

Sallis, J. F., Alcaraz, J. E., McKenzie, T. L., Hovell, M. F., Kolody, B. \& Nader, P. R. (1992a). Parental behavior in relation to physical activity and fitness in 9-year-old children. American Journal of Diseases of Children 146, 1383-1388.

Sallis, J. F., Hovell, M. F., Hofstetter, C. R. \& Barrington, E. (1992b). Explanation of vigorous physical activity during two years using social learning variables. Social and Scientific Medicine 34, 25-32.

Schulz, L. O. \& Schoeller, D. A. (1994). A compilation of total energy expenditures and body weights in healthy adults. American Journal of Clinical Nutrition 60, 676-681.

Segal, K. R. \& Dietz, W. H. (1991). Physiologic responses to playing a video game. American Journal of Diseases of Children 145, 1034-1036.

Simoes, E. J., Byers, T., Coates, R. J., Serdula, M., Mokdad, A. H. \& Heath, G. W. (1995). The association between leisure-time physical activity and dietary fat in American adults. American Journal of Public Health 85, 240-244.

Singh, J., Prentice, A. M., Diaz, E., Coward, W. A., Ashford, J., Sawyer, M. \& Whitehead, R. G. (1989). Energy expenditure of Gambian women during peak agricultural activity as measured by the doubly-labelled-water method. British Journal of Nutrition 62,315-329.

Stephens, T., Jacobs, D. R. Jr \& White, C. C. (1985). A descriptive epidemiology of leisure-time physical activity. Public Health Reports 100, 147-158.

Story, M. \& Faulkner, P. (1990). The prime time diet: a content analysis of eating behavior and food messages in television program content and commercials. American Journal of Public Health 80, 738-740.

Taras, H. L. \& Gage, M. (1995). Advertised foods on children's television. Archives of Pediatric and Adolescent Medicine 149, 649-652.

Taras, H. L., Sallis, J. F., Patterson, T. L., Nader, P. R. \& Nelson, J. A. (1989). Television's influence on children's diet and physical activity. Journal of Developmental and Behaviorial Pediatrics 10, 176-180.

Troisi, R. J., Heinold, J. W., Vokonos, P. S. \& Weiss, S. T. (1991). Cigarette smoking, dietary intake, and physical activity: effects on body fat distribution - the Normative Aging Study. American Journal of Clinical Nutrition 53, 1104-1111

Tucker, L. A. \& Bagwell, M. (1991). Television viewing and obesity in adult females. American Journal of Public Health 81, 908-911.

Tucker, L. A. \& Friedman, G. M. (1989). Television viewing and obesity in adult males. American Journal of Public Health 79, 516-518.

Wannamethee, G. \& Shaper, A. G. (1992). Physical activity and stroke in British middle aged men. British Medical Journal 304, 597-601. 
Washburn, R. A., Kline, G., Lackland, D. T. \& Wheeler, F. C. (1992). Leisure time physical activity: are there black/white differences? Preventive Medicine 21, 127-135.

Williams, T. M. \& Handford, A. G. (1986). Television and other leisure activities. In The Impact of Television a Natural Experiment in Three Communities, pp. 143-213 [T. M. Williams, editor]. New York: Academic Press Inc.

Williamson, D. E., Madans, J., Anda, R. F., Kleinman, J. C., Kahn, H. S. \& Byers, T. (1993). Recreational physical activity and ten-year weight change in a US national cohort. International Journal of Obesity 17, 279-286.

Wolf, A. M., Gortmaker, S. L., Cheung, L., Gray, H. M., Herzog, D. B. \& Colditz, G. A. (1993). Activity, inactivity, and obesity: racial, ethnic, and age differences among schoolgirls. American Journal of Public Health 83, 1625-1627. 